\title{
A structural equation model analysis of the effects of emotional labor and job stress on depression among nurses with long working hours: Focusing on the mediating effects of resilience and social support
}

\author{
Hye-Sun Jung ${ }^{\mathrm{a}, *}$ and Eun-mi Baek ${ }^{\mathrm{b}}$ \\ ${ }^{a}$ Professor, Department of Preventive Medicine, College of Medicine, The Catholic University of Korea, \\ Republic of Korea \\ ${ }^{\mathrm{b}}$ Research Professor, Department of Preventive Medicine, College of Medicine, The Catholic University \\ of Korea, Republic of Korea
}

Received 12 December 2018

Accepted 29 July 2019

\begin{abstract}
.
BACKGROUND: Recently, hospital services have undergone massive changes. As global competition intensifies and informed patients require improved medical services, nurses' depression has increased.

OBJECTIVE: We investigated the effect of emotional labor and job stress on depression in nurses with long working hours via structural equation modeling.

METHODS: The data were collected in three general hospitals with 300 beds or more from August 31 to September 12, 2016, and 400 nurse practitioners agreed to participate. We retrieved 350 self-reported questionnaires in total, of which 291 were analyzed (excluding 33 containing unidentifiable values and 26 outliers).

RESULTS: The emotional labor of nurses with long working hours influenced depression, whereas job stress did not. Resilience had a negative mediating effect on the relationship between emotional labor and depressive symptoms. Social support had negative mediating effects on the relationship between job stress and depression.

CONCLUSIONS: To promote the mental health of nurses in Korea, policies must decrease nurses' working hours and maintain work environments that enable them to demonstrate their full competency. Thus, it is necessary to limit long hours and implement structures and systems that promote compliance with these limitations.
\end{abstract}

Keywords: Emotional labor, job stress, depression, nurses

\section{Introduction}

*Address for correspondence: Hye-Sun Jung, Department of Preventive Medicine, College of Medicine, The Catholic University of Korea, 222 Banpo-daero, Seocho-gu, Seoul 00591, Republic of Korea. Tel.: +82 22258 7868; Fax: +82 532 3820; E-mail: hyesun@catholic.ac.kr.

Recent years have seen a demand for massive change in hospital services. However, as global competition intensifies and more knowledgeable patients demand higher quality medical services, depression 
has become increasingly aggravated among nurses [1]. According to the results of the 4th Korean Working Conditions Survey, conducted by the Korea Occupational Safety Health Agency, 35.4\% of nurses complained of depression in 2014. This suggests that depression is a serious problem among nurses [2]. Moreover, nurses, who provide direct services to patients through teamwork with various other occupations, have high emotional labor and job stress, both of which can have a negative effect on mental health. In fact, increasing job stress has been shown to increase depression in nurses [3]. Therefore, it is an important task for hospitals to improve depression caused by nurses' emotional labor and job stress.

Long working hours can increase emotional labor and job stress, and thus are a possible means of aggravating depression. According to Park and Kwak [4], nurses worked on average for 2,544 hours annually in 2015 , or roughly 54 more days than the average worker in South Korea and 97 more days than the average worker in Organization for Economic Co-operation and Development (OECD) countries. However, few studies have investigated the relationship between long working hours and depression [5, 6] - as such, it is important for researchers to examine this relationship. Furthermore, it is necessary to determine whether increasing resilience and social support can mitigate the potential negative effect of long working hours on depression. Resilience, which refers to the ability to cope with and successfully adapt to new environments or difficulties [7], has been shown to play a mediating role in nurses' ability to adapt to their working environment $[8,9]$.

The present study analyzed the pathways through which emotional labor and job stress affect depression in nurses working for long hours at hospitals, and investigated whether resilience and social support act as mediating variables in these pathways.

\section{Methods}

\subsection{Study design}

This was a cross-sectional, structural equation modeling study aiming to test the goodness of fit of a model explaining the effect of emotional labor and job stress on depression in nurses with long working hours.

\subsection{Research model}

A model was constructed based on a previous literature review of depression in nurses with long working hours. Emotional labor and job stress were used as exogenous variables, whereas resilience, social support, and depression were considered endogenous variables.

\subsection{Study subjects}

Questionnaires were distributed to nurses at three general hospitals with more than 300 beds, located in Seoul, Gangwon, and Daejeon, through the health managers of those hospitals. The questionnaires were distributed to 400 selected participants; of these, 350 returned completed questionnaires. We excluded 33 questionnaires with weak answers and 26 who reported working for less than 10 hours per day-therefore, the data of 291 nurses with long working hours (more than 10 hours per day) were included in the final analysis. Our sample size satisfies the recommendation of 15 subjects for each variable [10].

\subsection{Data collection}

Data were collected between August 31 and September 12, 2016. The purpose and methods of this study were explained to the health managers at the hospitals, and their consent to conduct the study was obtained. Anonymous self-report questionnaires were distributed to nurse practitioners who consented to participate in the study. This study was approved by the Institutional Review Board (IRB) of the Catholic University (IRB approval number MC16QISE0101) in August 2016. The data were collected as per the approved protocol.

\subsection{Tools}

\subsubsection{General characteristics}

The following general characteristics of the participants were assessed via 13 items, which were revised and supplemented from the items of the Korea National Health and Nutrition Examination Survey (KNHANES) to fit our study design: sex, age (20-29 years, 30-39 years, and 40-49 years), marital status (married and single), smoking (yes or no), regular exercise ( $\geq 3 /$ week, 1-2/week, $<1 /$ week, and none), alcohol drinking ( $\geq 2-3 /$ week, $2-4 /$ month, $1 /$ month, $<1 /$ month, and none), sleep duration ( $<8$ hours, $\geq 12$ and $<24$ hours, and $\geq 10$ hours), regular meals (regular, moderate, and irregular), fatigue (no, moderate, 
and yes), experience of sadness and despair (yes or no), suicidal thoughts (yes or no), and suicidal attempts (yes or no).

\subsubsection{Job-related characteristics}

The following job-related characteristics were assessed in seven items: work unit (outpatients ward and general ward), shift work (yes or no), night shift ( $<6$ days/week and $\geq 6$ days/week), average working hours per day ( $\geq 10$ and $<11, \geq 11$ and $<13$, and $\geq 13)$, hours in direct contact with patients per day $(<6$ and $\geq 6$ ), clinical career ( $<12$ months, $\geq 12$ and $<24$ months, $\geq 24$ and $<36$ months, and $\geq 36$ months), and job satisfaction (satisfied, moderate, and dissatisfied).

\subsubsection{Emotional labor}

Emotional labor was measured with the emotional labor tool originally developed by Morris and Feldman [11] and revised and updated by Kim [12].

\subsubsection{Job stress}

To measure job stress, the 24-item Korean Occupational Stress Scale Short Form (KOSS-SF) developed by Jang et al. [13] was used. Three items on physical environment, which are assessed in the Basic Form, were added to these 24 , making the total number of items in this scale 27.

\subsubsection{Resilience}

For resilience, we used the 25-item Korean Connor-Davidson Resilience Scale (CD-RISC), originally developed by Connor and Davidson [14] and translated and validated by Baek [15].

\subsubsection{Social support}

Social support was measured with the tool developed by Jung [16], based on the studies of Barry, Parasuraman, and Zeithaml [17] and Redman and Mathews [18], using the items established by House [19] as a reference. Jung's nine-item tool was specifically designed for South Korea. We measured the degree of social support with three aspects (supervisor support, collegial support, and organizational support).

\subsubsection{Depression}

Depression was measured using the Center for Epidemiologic Studies Depression Scale (CES-D), developed by Radloff [20] in 1977. This is a selfreport depression scale comprising 20 items; we used the Korean CES-D developed and studied by Cho and Kim [21].

\subsection{Data analysis}

First, the participants' general characteristics and the main variables were analyzed through descriptive statistics, such as the frequency, mean, and standard deviation. Cronbach's alpha was used to test the reliability of the tools: alpha coefficients exceeding 0.7 were interpreted to represent good reliability (i.e., the questions/items comprising the tool have high internal consistency). Second, multicollinearity between measured variables was analyzed through Pearson's correlation coefficient. Third, using the multivariate normality test, the normality of the sample was analyzed in terms of the mean, standard deviation, skewness, and kurtosis. Fourth, to analyze the structural equation model, a two-step protocol was followed. We first estimated the research model, and then the structural model. A confirmatory factor analysis was conducted to evaluate the validity of the latent variables in the research model. Fifth, the goodness of fit of the hypothetical model representing the participants was assessed by estimating the $\chi^{2}$ value, $\chi^{2} / \mathrm{df}$, root mean square error of approximation (RMSEA), goodness of fit index (GFI), adjusted goodness of fit index (AGIF), normed fit indices (NFI), comparative fit index (CFI), and Tucker-Lewis index (TLI). Sixth, to test the significance of the structural model, the regression weights, standard errors, critical ratios, and $p$-values were examined. To test the statistical significance of the total and indirect effects of the research model, we used the bootstrapping method. Finally, to test the significance of the mediating effects, we conducted a Sobel test. Data analyses were conducted using IBM SPSS Statistics 23.0 and AMOS 23.0.

\section{Results}

\subsection{Reliability of the tools}

As all coefficients exceeded 0.7 in this study, their reliability was interpreted as good. Note that in the job stress tool, one question each was deleted from the lack of reward and organizational system subscales before analysis, because the coefficients of these subscales were below 0.5 . The reliability coefficient was above 0.7 after this revision. In the resilience tool, the 
Table 1

Reliability analysis of measurement tools

\begin{tabular}{|c|c|c|c|c|c|}
\hline \multicolumn{2}{|c|}{$\begin{array}{ll}\text { Variables } \\
\end{array}$} & \multicolumn{2}{|c|}{ Before } & \multicolumn{2}{|c|}{ After } \\
\hline & & $\begin{array}{c}\text { Cronbach's } \\
\alpha\end{array}$ & $\begin{array}{l}\text { Number } \\
\text { of items }\end{array}$ & $\begin{array}{c}\text { Cronbach's } \\
\alpha\end{array}$ & $\begin{array}{l}\text { Number } \\
\text { of items }\end{array}$ \\
\hline \multirow[t]{3}{*}{ Emotional labor } & Frequency of emotional display & 0.772 & 3 & & 3 \\
\hline & Attentiveness to required display rules & 0.625 & 3 & & 3 \\
\hline & Emotional dissonance & 0.756 & 3 & & 3 \\
\hline \multirow{7}{*}{ Job stress } & Job demand & 0.783 & 4 & & 4 \\
\hline & Insufficient job control & 0.573 & 4 & & 4 \\
\hline & Interpersonal conflict Job insecurity & 0.659 & 3 & & 3 \\
\hline & Job insecurity & 0.683 & 2 & & 2 \\
\hline & Organizational system & 0.719 & 4 & & 4 \\
\hline & Lack of reward & -0.454 & 3 & .724 & 2 \\
\hline & Occupational climates & 0.381 & 4 & .586 & 3 \\
\hline \multirow[t]{5}{*}{ Resilience } & Hardiness & 0.892 & 9 & & 9 \\
\hline & Persistence & 0.931 & 8 & & 8 \\
\hline & Optimism & 0.882 & 4 & & 4 \\
\hline & Support & 0.399 & 2 & delete & 0 \\
\hline & Faith & 0.863 & 2 & & 2 \\
\hline \multirow{3}{*}{ Social support } & Supervisor support & 0.840 & 3 & & 3 \\
\hline & Collegial support & 0.896 & 3 & & 3 \\
\hline & Organizational support & 0.871 & 3 & & 3 \\
\hline Depression & Depression & 0.942 & 20 & & 20 \\
\hline Total & & 87 & & 83 & \\
\hline
\end{tabular}

support subscale was deleted because the coefficient of the subscale was below 0.5 (Table 1).

\subsection{General and mental health characteristics}

A self-report survey was conducted on 291 nurses working at three general hospitals. Regarding the mental health variables, $82.1 \%$ of the participants slept for less than eight hours; $22 \%$ experienced despair; 5.2\% had suicidal thoughts; and 1.4\% attempted suicide (Table 2).

\subsection{Job-related characteristics}

Regarding the participants' job-related characteristics, $53.6 \%$ worked in shifts and 56\% worked the night shift less than six days per week. In terms of average working hours, $50.5 \%$ worked for $\geq 10$ and $<11$ hours; $45.4 \%$, for $\geq 11$ and $<13$ hours; and $3.8 \%$, for 13 hours or more. The participants worked for an average of 10.82 hours per day (Table 3 ).

\subsection{Descriptive statistics of main variables}

On average, participants scored 3.37 out of 5 for emotional labor and 49.52 out of 100 for job stress. The average score for resilience was 2.91 out of 5 , whereas that for social support was 3.58 out of 5 . The participants also obtained an average score of 16.69 out of 60 on the depression scale (Table 4).

\subsection{Goodness of fit of tools}

The $\chi^{2}(\mathrm{df}=180)$ value was significant at 458.839 $(p<.001)$; however, this was probably due to sample size and model complexity. The other indices of goodness of fit met the recommended standards: $\mathrm{GFI}=0.866$, AGFI $=0.828$, TLI $=0.909$, root mean square residual $(\mathrm{RMR})=0.032$, and $\mathrm{RMSEA}=0.073$. Although GFI $=0.866$ and NFI $=0.879$ did not meet the recommended standards, the differences were not great; therefore, the hypothetical model had a good overall fit.

\subsection{Test of the research model}

Emotional labor exerted a significant negative influence on resilience $(\beta=-2.168, p<.05)$. Likewise, job stress exerted a significant negative influence on social support $(\beta=-3.407, p<.001)$. Both resilience $(\beta=-4.220, p<.001)$ and social $\operatorname{support}(\beta=-3.314, p<.001)$ exerted significant negative influences on depression. In contrast, emotional labor exerted a significant positive influence on depression $(\beta=4.424, p<.001)$ (Table 5).

\subsection{Final model selection}

Based on the results, the following final research model was suggested. Resilience had a significant mediating effect on the relationship between emo- 
Table 2

General characteristics and mental health of the subjects $(\mathrm{N}=291)$

\begin{tabular}{|c|c|c|c|}
\hline Variables & Category & $N$ & $\%$ \\
\hline \multirow[t]{2}{*}{ Sex } & Male & 17 & 5.8 \\
\hline & Female & 274 & 94.2 \\
\hline \multirow[t]{3}{*}{ Age (years) } & $20-29$ & 170 & 58.4 \\
\hline & $30-39$ & 88 & 30.2 \\
\hline & $40-49$ & 33 & 11.3 \\
\hline \multirow[t]{2}{*}{ Smoking } & Yes & 3 & 1.0 \\
\hline & No & 288 & 99.0 \\
\hline \multirow[t]{2}{*}{ Marital status } & Married & 191 & 65.6 \\
\hline & Single & 100 & 34.4 \\
\hline \multirow[t]{4}{*}{ Regular exercise } & $\geq 3$ /week & 14 & 4.8 \\
\hline & $\overline{1}-2 /$ week & 159 & 54.8 \\
\hline & $<1 /$ week & 43 & 14.8 \\
\hline & None & 75 & 25.8 \\
\hline \multirow[t]{5}{*}{ Alcohol drinking } & $\geq 2-3 /$ week & 36 & 12.4 \\
\hline & 2-4/month & 67 & 23.0 \\
\hline & $1 /$ month & 95 & 32.6 \\
\hline & $<1 /$ month & 78 & 26.8 \\
\hline & None & 15 & 5.2 \\
\hline \multirow{3}{*}{ Regular meal } & Regular & 67 & 23.0 \\
\hline & Moderate & 46 & 15.8 \\
\hline & Irregular & 178 & 61.2 \\
\hline \multirow[t]{3}{*}{ Fatigue } & No & 8 & 2,7 \\
\hline & Moderate & 41 & 14.1 \\
\hline & Yes & 242 & 83.2 \\
\hline \multirow[t]{3}{*}{ Sleep duration (hours) } & $<8$ & 239 & 82.1 \\
\hline & $\geq 8$ and $<10$ & 45 & 15.5 \\
\hline & $\geq 10$ & 7 & 2.4 \\
\hline \multirow[t]{2}{*}{ Experience of sadness and despair } & No & 227 & 78.0 \\
\hline & Yes & 64 & 22.0 \\
\hline \multirow[t]{2}{*}{ Suicidal thoughts } & No & 276 & 94.8 \\
\hline & Yes & 15 & 5.2 \\
\hline \multirow[t]{2}{*}{ Suicidal attempt } & No & 287 & 98.6 \\
\hline & Yes & 4 & 1.4 \\
\hline
\end{tabular}

tional labor and depression. Moreover, increased emotional labor was found to be associated with decreased resilience, while decreased resilience was associated with increased level of depression. Social support also had a significant mediating effect on the relationship between job stress and depression. Furthermore, it was observed that increased job stress was associated with decreased social support, while decreased social support was associated with increased level of depression (Fig. 1).

\section{Discussion}

The present structural equation modeling study examined whether emotional labor and job stress had a significant effect on depression in nurses with long working hours, and whether resilience and social support mediated these relationships. Nurses with long working hours were found to have higher levels of
Table 3

Job-related characteristics of the subjects $(\mathrm{N}=291)$

\begin{tabular}{|c|c|c|c|}
\hline Variables & Category & $n$ & $\%$ \\
\hline \multirow[t]{2}{*}{ Work unit } & Outpatients ward & 129 & $\overline{44.3}$ \\
\hline & General ward & 162 & 55.7 \\
\hline \multirow[t]{2}{*}{ Shift work } & Yes & 156 & 53.6 \\
\hline & No & 135 & 46.4 \\
\hline \multirow{2}{*}{$\begin{array}{l}\text { Night shift } \\
\text { (days/week) }\end{array}$} & $<6$ & 163 & 56.0 \\
\hline & $\geq 6$ & 128 & 44.0 \\
\hline \multirow{3}{*}{$\begin{array}{l}\text { Average working } \\
\text { time (hours/day) }\end{array}$} & $\geq 10$ and $<11$ & 147 & 50.5 \\
\hline & $\geq 11$ and $<13$ & 132 & 45.4 \\
\hline & $\geq 13$ & 11 & 3.8 \\
\hline \multirow{2}{*}{$\begin{array}{l}\text { Hours in direct } \\
\text { contact with } \\
\text { patients per day }\end{array}$} & $<6$ & 19 & 6.5 \\
\hline & $\geq 6$ & 272 & 93.5 \\
\hline \multirow{4}{*}{$\begin{array}{l}\text { Clinical career } \\
\text { (months) }\end{array}$} & $<12$ & 227 & 78.0 \\
\hline & $\geq 12$ and $<24$ & 26 & 8.9 \\
\hline & $\geq 24$ and $<36$ & 14 & 4.8 \\
\hline & $\geq 36$ & 24 & 8.2 \\
\hline \multirow[t]{3}{*}{ Job satisfaction } & Satisfied & 74 & 25.4 \\
\hline & Moderate & 94 & 32.3 \\
\hline & Dissatisfied & 123 & 42.3 \\
\hline
\end{tabular}

Table 4

Descriptive statistics (exogenous and endogenous variables)

\begin{tabular}{llcc}
\hline Latentvariables & Measures & Range & Mean \pm S.D \\
\hline Emotional labor & $\begin{array}{l}\text { Frequency of } \\
\text { emotional display }\end{array}$ & $1-5$ & $3.49 \pm 0.77$ \\
& $\begin{array}{l}\text { Attentiveness to } \\
\quad \text { required display }\end{array}$ & $1-5$ & $3.39 \pm 0.72$ \\
& $\quad$ rules & & \\
& Emotional dissonance & $1-5$ & $3.23 \pm 0.75$ \\
Job stress & Job demand & $1-4$ & $3.01 \pm 0.52$ \\
& Insufficient job & $1-4$ & $2.50 \pm 0.41$ \\
& $\quad$ control & & \\
& Interpersonal conflict & $1-4$ & $2.08 \pm 0.41$ \\
& Job insecurity & $1-4$ & $2.26 \pm 0.59$ \\
& Organizational system & $1-4$ & $2.56 \pm 0.48$ \\
& Lack of reward & $1-4$ & $2.60 \pm 0.57$ \\
& Occupational climates & $1-4$ & $2.40 \pm 0.49$ \\
Resilience & Hardiness & $1-5$ & $2.89 \pm 0.71$ \\
& Persistence & $1-5$ & $2.81 \pm 0.71$ \\
& Optimism & $1-5$ & $2.70 \pm 0.71$ \\
& Faith & $1-5$ & $2.88 \pm 0.71$ \\
Social support & Supervisor support & $1-5$ & $3.55 \pm 0.71$ \\
& Collegial support & $1-5$ & $3.70 \pm 0.62$ \\
& Organizational & $1-5$ & $3.48 \pm 0.65$ \\
& support & & \\
& Depression 1 & $0-3$ & $0.95 \pm 0.63$ \\
Depression & Depression 2 & $0-3$ & $0.83 \pm 0.65$ \\
& Depression 3 & $0-3$ & $0.93 \pm 0.66$ \\
& Depression 4 & $0-3$ & $0.63 \pm 0.70$ \\
\hline & & & \\
& & &
\end{tabular}

depression, in accordance with higher levels of emotional labor. This agrees with the findings of most previous studies $[22,23]$. Although job stress did not 
Table 5

Research model verification results

\begin{tabular}{|c|c|c|c|c|c|c|}
\hline Path & & & $\begin{array}{l}\text { Non-standardization } \\
\text { factor }\end{array}$ & $S E$ & $\begin{array}{c}\text { Standardization } \\
\text { factor }\end{array}$ & $C R$ \\
\hline Resilience & $\leftarrow$ & Emotional labor & -0.164 & 0.076 & -0.156 & $-2.168^{*}$ \\
\hline Social support & $\leftarrow$ & Job stress & -1.410 & 0.414 & -0.403 & $-3.407^{* * *}$ \\
\hline Social support & $\leftarrow$ & Emotional labor & -0.070 & 0.058 & -0.089 & -1.204 \\
\hline Resilience & $\leftarrow$ & Job stress & -0.731 & 0.377 & -0.156 & -1.940 \\
\hline Depression & $\leftarrow$ & Resilience & -0.202 & 0.048 & -0.235 & $-4.220^{* * *}$ \\
\hline Depression & $\leftarrow$ & Social support & -0.256 & 0.077 & -0.222 & $-3.314^{* * *}$ \\
\hline Depression & $\leftarrow$ & Emotional labor & 0.264 & 0.060 & 0.292 & $4.424^{* * *}$ \\
\hline Depression & $\leftarrow$ & Job stress & 0.482 & 0.310 & 0.120 & 1.556 \\
\hline
\end{tabular}

${ }^{*} p<0.05, * * p<0.01,{ }^{* * *} p<0.001$.

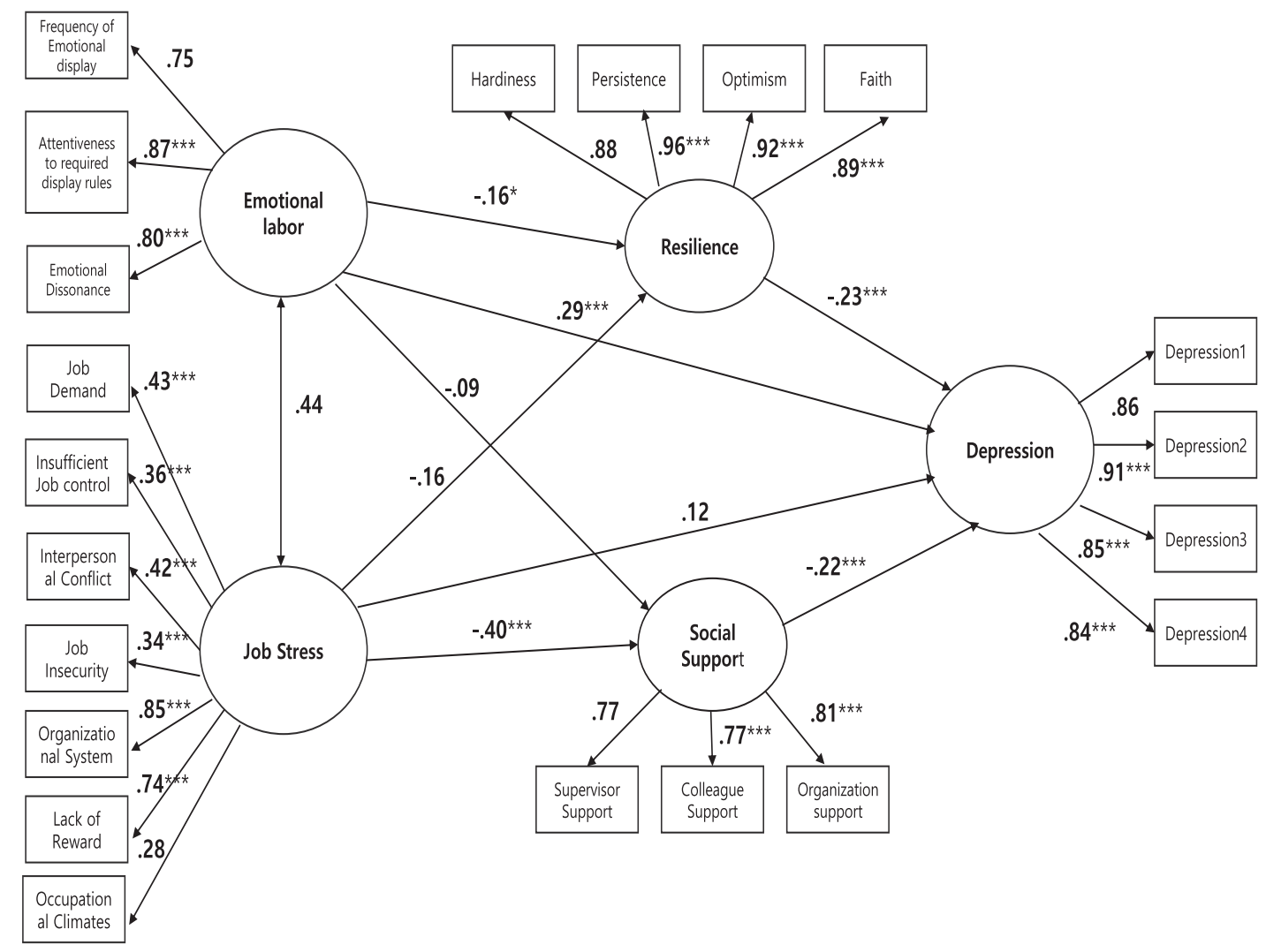

Fig. 1. Path diagram of study model. $* p<0.5, * * p<0.01, * * * p<0.001$.

exert any direct effect on depression, it had a significant indirect effect through social support. The relatively lower job stress score from the participants is considered to have been insufficient to exert a direct effect on depression. Therefore, replication studies should be conducted to investigate more subgroups of participants.

When the mediating effects of resilience were analyzed in the relationship between emotional labor and depression, resilience was found to be significantly negatively related to depression. Although many studies have investigated the effects of programs that promote resilience, only few have assessed the relationship between emotional labor, depression, and resilience. In Park et al.'s [24] investigation of the effects of resilience on the relationship between emotional labor and burnout in childcare teachers, resilience was found to exert different effects on the pathways through which surface and deep acting (aspects of emotional labor) affected burnout. Studies on ways to improve resilience have typically utilized education and stress relief programs for 
nurses, and have found that such programs increased nurses' resilience [25, 26]. Therefore, it is important to support nurses through encouraging their selfexpression, improving their competencies as clinical experts, and mentoring programs. Through these efforts, hospitals can continue to hire competent nurses and form good relationships with these nurses, thereby fostering a healthy organizational culture [26].

Social support was also found to have a significant mediating effect on the relationship between job stress and depression. In a study investigating the mediating effects of social support on the relationship between emotional labor and job stress in public welfare officials, social support exerted a similar effect as that observed in the present study [19]. This supports the finding that low psychosocial support exerts a negative influence on health [27], and that high social support from individuals and organizations can lower depression [28]. Another study conducted on employees of a Malaysian manufacturer of automobile parts reported that high social support can lower stress and protect against the development of depression disorder [29]. In a study on Chinese nurses, social support was found to have moderating effects on job stress and depression [30]. Moreover, improved social support was reported to decrease job stress and depression, which can be supported by the theory that social support exerts a buffering effect. The importance of social support must be emphasized because it can improve hospital nurses' ability to overcome frustration and solve problems by acting as an environmental coping resource. With regard to social support for problems arising from the emotional requirements of the organization, organizational support along with warm words and authentic emotional support from colleagues or superiors can decrease the negative aspects of emotional labor and job stress [31].

The present study is significant in the following aspects. First, although many studies have investigated the effects of night shifts and shift work, only a few have investigated long working hours. The present study is thus significant in that it assessed the relationships of emotional labor and job stress with depression in nurses with long working hours. Second, the mediating effects of resilience and social support were analyzed to determine whether these constructs are important for decreasing depression; this is significant because the findings can contribute to the development of methods aimed at decreasing depression in nurses. Finally, although many studies have investigated the effects of emotional labor, job stress, resilience, and social support on depression, the present study expanded on these studies by integrating all the variables into a single structural model.

The present study has several limitations. First, the subjects of this study are nurses working in general hospitals with more than 300 beds. In general, in Korea, the working conditions of general hospitals are better than those of smaller hospitals. Therefore, there are limitations in applying the results of study to nurses working in hospital with 300 beds or less. Second, we included the frequency of night shift work in analysis, but not the average quantity of work shifts expressed in hours. Finally, we could not include some factors in analysis that could affect depression, such as socioeconomic status, past medical history, and family history.

\section{Conclusion}

This structural equation modeling study investigated the effect of emotional labor and job stress on depression in nurses with long working hours. Emotional labor was found to exert a significant effect on depression in nurses with long working hours. When the mediating effects of resilience and social support were analyzed, we found that resilience mediated the relationship between emotional labor and depression. As for the effect of job stress on depression, social support was found to have a mediating effect.

The fact that emotional labor was significantly associated with depression in nurses with long working hours suggests that it is necessary to prepare measures to reduce the negative effects of emotional labor within the medical institutions. Moreover, it is necessary to develop and apply programs that can promote resilience, as this could help reduce depression caused by emotional labor among nurses with long working hours. It is also necessary to increase social support in order to potentially reduce the depressive effect of job stress. Finally, measures and policies that limit nurses' working hours are necessary.

\section{Acknowledgments}

We would like to thank Editage (www.editage. com) for English language editing and publication support services. 


\section{Conflict of interest}

None to report.

\section{Funding}

None to report.

\section{References}

[1] Goh MS, Lee HS, Goh MS. Effects of nurses' social capital and job engagement on nursing performance: focused on the mediating effects of organizational citizenship behavior. J Korean Acad Nurs Adm. 2017;23(1):42-51.

[2] Choi ES, Jeon GS. The impacts of Psychosocial work environments on depressive symptoms among Korean registered nurses. Korean J Occup Health Nurs. 2017;26(1):30-39.

[3] Mann S, Cowburn J. Emotional labour and stress within mental health nursing. J Psychiatr Mental Health Nurs. 2005; 12(2):154-162.

[4] Kwak SS, Park YC. Contracted research on ways to improve labor force supply and working conditions in public health and medicine. Seoul: Work in Organizational Innovation Research Institute;2015.

[5] Driesen K, Jansen NW, Kant I, et al. Depressed mood in the working population:associations with work schedules and working hours. Chronobiol Int. 2010;27(5):1062-1079.

[6] Takada M, Suzuki A, Shima S, et al. Associations between lifestyle factors, working environment, depressive symptoms and suicidal ideation: a large-scale study in Japan. Ind Health. 2009;47(6):649-655.

[7] Cicchetti D, Garmezy N. Prospects and promises in the study of resilience. Dev Psychopathol. 1993;5:497-502.

[8] Hart PL, Brannan JD, De Chesnay M. Resilience in nurses: an integrative review. J Nurs Manag. 2014;22(6):720-734.

[9] Lee IJ. Moderating effects of life problems, social support on the relationship between depression and suicidal ideation of older people. Health Soc Welf Rev. 2011;31(4):34-62.

[10] Cheung MWL. Multivariate meta-analysis as structural equation models. Struct Equ Model. 2013;20(3):429-454.

[11] Morris JA, Feldman DC. Managing emotions in the workplace. J Manag Issues. 1997;9(3):257-274.

[12] Kim MJ. Relations of OCB and the hotel employee's performance attitude. J Tour Soc. 1998;22(2):278-284.

[13] Jang SJ, Goh SB, Kang DM, et al. Developing an occupational stress scale for Korean Employees. Ann Occup Environ Med. 2005;17(4):297-317.

[14] Connor KM, Davidson JR. Development of a new resilience scale: The Connor-Davidson Resilience Scale (CD-RISC). Depress Anxiety. 2003;18(2):76-82.
[15] Baek HS. Reliability and validity of the Korean Version of the Connor-Davidson Resilience Scale (K-CD-RISC). Daejeon: Eulji University; 2010.

[16] Jung CH. A study on the effect emotional labor on the job stress and job burnout of social work civil servant of SMG: Focused on regulation effect of social support [PhD thesis]. Seoul: University of Seoul; 2014.

[17] Berry LL, Parasuraman A, Zeithaml VA. Improving service quality in America: lessons learned. Acad Manag Exec. 1994;8(2):32-45.

[18] Mathews BP, Redman T. Managerial recruitment advertisements-just how market-orientated are they? Int J SelAssesst. 1998;6(4):240-248.

[19] House JS, Wells JA, Landerman LR, et al. Occupational stress and health among factory workers. J Health Soc Behav. 1979;20(2):139-160.

[20] Radloff LS. The CES-D scale: A self-report depression scale for research in the general population. Appl Psychol Measure. 1977;1(3):385-401.

[21] Cho MJ, Kim GH. Diagnostic validity of the CES-D (Korean Version) in the assessment of DSM-III-R major depression. J Korean Neuropsychiatr Assoc. 1993;32(3):381-399.

[22] Kim WB, Lee KY, Lee GL. Work environment and stress of emotional laborers. Korean J Soc. 2012;46(2):123-149.

[23] Ashforth BE, Humphrey RH. Emotional labor in service roles: the influence of identity. Acad Manag Rev. 1993;18(1):88-115.

[24] Park DP, Lee JY. The effects of emotional labor on burnout: the moderating and mediating effects of resilience in child care teachers. J Future Early Child Educ. 2016;23(2):53-70.

[25] Cameron F, Brownie S. Enhancing resilience in registered aged care nurses. Australas J Ageing. 2010;29(2):66-71.

[26] McAllister M, McKinnon J. The importance of teaching and learning resilience in the health disciplines: a critical review of the literature. Nurse Educ Today. 2009;29(4):371-379.

[27] Jung GY, Lee HJ, Lee YI, et al. The effects of job stress for depression in clinical nurses. Korean J Occup Health Nurs. 2007;16(2):158-167.

[28] Kim HJ, Kim JH. Emotional labor, social support, and depressive symptoms of clinical nurses in a province, Korea. Korean J Occup Health Nurs. 2011;20(3):308-318.

[29] Rusli BN, Edimansyah BA, Naing L. Working conditions, self-perceived stress, anxiety, depression and quality of life: a structural equation modelling approach. BMC Public Health. 2008;8(1):48.

[30] Wu H, Ge CX, Sun W, et al. Depressive symptoms and occupational stress among Chinese female nurses: the mediating effects of social support and rational coping. Res Nurs Health. 2011;34(5):401-407.

[31] Yeom YH, Kim HJ. Effects of compassion satisfaction and social support in the relationship between compassion fatigue and burnout in hospital nurses. J Korean Acad Nurs. 2012;42(6):870-878. 